Revista Brasileira de Cartografia

ISSN 1808-0936 | https://doi.org/10.14393/revbrascartogr

Sociedade Brasileira de Cartografia, Geodésia, Fotogrametria e Sensoriamento Remoto

\title{
O Cenário de Editais de Licitação Pública de Sistema de Informação Territorial para Administrações Municipais: Diagnóstico e Proposta de Requisitos Utilizando Técnicas de Engenharia de Requisitos
}

\section{The Public Bidding Scenario of Land Information System for Municipal Administrations: Diagnosis and Requirements Proposal Using Requirements Engineering Techniques}

Everton Leandro Nubiato ${ }^{1}$ e Luciene Stamato Delazari ${ }^{2}$

1 Universidade Federal do Paraná, Departamento de Geomática, Curitiba, Brasil.nubiato@ hotmail.com ORCID: https://orcid.org/0000-0002-8071-3304

2 Universidade Federal do Paraná, Departamento de Geomática, Curitiba, Brasil. luciene@ ufpr.br

ORCID: https://orcid.org/0000-0003-0018-085X

Resumo: A gestão do espaço territorial urbano é uma necessidade e uma obrigação dos municípios brasileiros que precisam de instrumentos capazes de fornecer conhecimento a respeito do território. Neste sentido, as administrações públicas municipais têm buscado soluções eficientes e eficazes que proporcionem a ordenação, o controle e a manutenção do espaço territorial, as quais permitam a conjugação de dados cadastrais, bases cartográficas e processos de gestão territorial, ou seja, há demanda por aquisição de sistemas de informação territorial para atender às necessidades por gestão do espaço urbano. Para se obter um sistema de informação territorial que possa ter critérios de qualidade e desempenho bem definidos e conhecidos do mercado, a fim de subsidiar a administração pública em processos licitatórios, pode-se aplicar técnicas da engenharia de software para elicitação, análise, documentação e validação de requisitos do sistema. Todavia, o desenvolvimento de um projeto de engenharia de software para definição de requisitos de sistema não é algo simples e requer capacidade técnica e profissional, além de recursos financeiros, o que pode ser um grande desafio para as administrações públicas municipais. Neste contexto, a proposta deste artigo é apresentar os resultados da aplicação de técnicas de engenharia de software na verificação e validação das especificações técnicas encontradas em editais de licitação de administrações públicas municipais, a fim de registrar o cenário brasileiro, bem como fazer uma proposta inicial de um documento de requisitos o qual possa contribuir para uma futura padronização de sistemas de informação territorial em administrações públicas municipais. Palavras-chave: Sistema de Informação Territorial. Gestão Territorial. Soluções de Geoinformação. Engenharia de Requisitos.

\begin{abstract}
The management of the urban land space is a necessity and an obligation of Brazilian municipalities that need instruments capable of providing knowledge about their territory. In this sense, the local governments have sought efficient and effective solutions that provide ordering, control and maintenance of the land space, which allow the integration of cadastre data, cartographic data and land management processes, in other words, there is demand for acquisition of land information systems in order to meet the needs for urban land management. In order to obtain a land information system that can have well defined criteria of quality and performance of the market, to support the public administration in bidding processes, it is possible to apply software engineering techniques for elicitation, analysis, documentation and validation of system requirements. Nevertheless, the development of a software engineering project to define system requirements is not something simple and requires technical and professional skills as well as financial resources, which can be a major challenge for local governments. In this context, the purpose of this paper is to present the results of the application of software engineering techniques in the verification and validation of the technical specifications found in bidding notices for municipal public administrations, in order to present the Brazilian scenario and an initial proposal of a requirements document which can contribute to a future standardization of territorial information systems for municipal public administrations.
\end{abstract}

Keywords: Land Information System. Land Management. Requirements Engineering. Geoinformation Solutions.

\section{INTRODUÇÃO}

A ordenação, o controle, o desenvolvimento e a manutenção do espaço territorial urbano, conforme consta no inciso VIII artigo 30 e no artigo 182 da Constituição Brasileira de 1988 (BRASIL, 1988), é uma 
competência atribuída aos municípios, os quais a externalizam por iniciativas e ações da gestão pública municipal dos poderes executivo e legislativo. A gestão territorial urbana, conciliando metodologias e técnicas de administração e planejamento, proporciona à administração pública municipal ferramentas para controle do espaço urbano de forma a garantir as necessidades dos cidadãos, bem como auxiliar no cumprimento de atribuições legais dos administradores públicos municipais (AMORIM et al., 2015).

Para se praticar a gestão de um território é essencial que se tenha pleno conhecimento da constituição do espaço formador deste território, da extensão geográfica sobre a qual necessita ordenação e controle público. Por isso, os instrumentos que auxiliam o conhecimento do território, como os levantamentos cadastrais e cartográficos, ganharam destaque principalmente após a publicação da Lei de Responsabilidade Fiscal (Lei Complementar Federal 101/2000; BRASIL, 2000) e do Estatuto das Cidades (Lei Federal 10.257/2001; BRASIL, 2001), que exigem de todos os municípios a manutenção do mapeamento da sua extensão territorial e o conhecimento quantitativo e qualitativo da ocupação do território urbano, com vistas à adequada gestão fiscal e urbanística (AMORIM et al., 2015).

A melhoria da gestão territorial urbana pode ser alcançada com aumento da capacidade técnica e profissional, implementação de novas tecnologias para o controle da ocupação urbana, o desenvolvimento do cadastro técnico municipal, a elaboração e a manutenção da cartografia cadastral municipal, a implantação de um Sistema de Informação Territorial (SIT), ou seja, há uma série de ações e políticas que podem promover uma gestão territorial urbana mais adequada, dentre elas o desenvolvimento e a implantação de um sistema de informação voltado ao cadastro técnico multifinalitário (ERBA, LIMA JUNIOR, OLIVEIRA, 2005).

Um SIT, cujo emprego nos processos administrativos municipais pode auxiliar no controle e ordenamento do espaço territorial (SCARASSATTI et al., 2014), pode ser adquirido pela administração pública através de um processo licitatório de contratação de bens e serviços de informática, o que pela Lei Federal 8.666/1993 (BRASIL, 1993) deve-se adotar obrigatoriamente o tipo de licitação pública denominada técnica e preço. Contudo, também há previsão legal do emprego de outro tipo de licitação nos casos indicados em decreto do poder executivo, sem restringir a modalidade de licitação.

Por requerer um processo mais célere, e para muitos administradores públicos uma forma de garantir o menor preço por bens e serviços, a modalidade de licitação do tipo pregão, prevista na Lei Federal 10.520/2002 (BRASIL, 2002) e que faz uso do tipo menor preço, tem sido amplamente empregada pelas administrações públicas em todas as esferas. Conforme a previsão legal estabelecida pela Lei Federal 10.520/2002 (BRASIL, 2002) e ratificada pela nota técnica $\mathrm{n}^{\circ}$ 02/2008 - SEFTI/TCU (BRASIL, 2008), para a administração municipal obter um sistema informatizado, como produto e ou serviço, empregando no processo licitatório a modalidade pregão, é necessário que o edital de aquisição tenha definições objetivas e claras dos padrões de desempenho e qualidade por meio de especificações usuais de mercado.

Entretanto, em editais de licitação publicados por administrações públicas entre janeiro de 2016 e abril de 2019, para aquisição de sistemas de informação territorial (SIT) e produtos e serviços relacionados à modernização do sistema de gestão cadastral, percebe-se que não há uma padronização na definição dos requisitos do sistema. Os motivos pelos quais as especificações técnicas encontradas nos editais de aquisição de SIT não apresentam uma padronização em seus requisitos podem estar relacionados à diversos fatores, como: falta de capacitação técnica e profissional, escassez de recursos, baixo volume de investimentos em planejamento urbano, deficiência nos processos de gestão territorial, entre outros.

Sendo assim, aplicar métodos de elicitação de requisitos por meio de técnicas de engenharia de requisitos (ER), a fim de elaborar uma documentação padronizada para especificação de SIT, pode ser um meio para ajudar os gestores públicos municipais na contratação e aquisição de produtos e serviços de implantação de SIT, o que poderá tornar a modernização do sistema de gestão territorial mais efetiva a uma maior quantidade de municípios.

Deste modo, o objetivo principal deste artigo é apresentar um diagnóstico geral das especificações técnicas encontradas em editais de licitação de administrações públicas municipais, entre janeiro de 2016 e abril de 2019, bem como apresentar uma proposta inicial de especificação de requisitos para módulos específicos de um sistema em um documento técnico sistematizado e estruturado, gerado a partir de técnicas da engenharia de requisitos (ER), para auxiliar os gestores públicos municipais na aquisição e implantação de 
sistema de informação geográfica (SIG), com ênfase na gestão territorial urbana.

A existência de uma documentação padronizada com orientações claras e objetivas, a qual permita guiar os gestores de municípios que possuem menor capacidade de investimento e menos capacitação técnica e profissional no processo de aquisição e implantação de um sistema de informação territorial, pode permitir que um número maior de municípios possa implantar um SIT com menor custo e maior efetividade, a fim de atender às necessidades de controle e ordenamento do espaço territorial urbano.

$\mathrm{O}$ escopo da pesquisa teve relação com o conjunto de funcionalidades que foram identificadas sobre o material analisado, uma vez que o universo de funcionalidades de um sistema de geoinformação, como um SIT, pode conter é ilimitado. Sendo assim, a pesquisa se preocupou em levantar e analisar os editais de referência com a maior abrangência possível, a partir de técnicas engenharia de requisitos aplicáveis dentro do prazo de execução imposto, o que limitou o uso de técnicas tradicionais como a utilização de entrevistas com usuários e o mapeamento de processos, assim como não especializou as necessidades por porte da administração ou pelo volume de investimento disponível na contratação de produtos e ou serviços de geoinformação. Deste modo, a especificação das funcionalidades de acordo com a metodologia proposta foi limitada em quantidade de módulos e suas funções, para tornar a pesquisa finita. Outra limitação relacionada ao escopo foi a especificação dos componentes de um sistema de geoinformação, não sendo gerado com este estudo especificações relacionadas aos itens de geovisualização como simbologia de apresentação dos elementos gráficos ou estrutura geométrica de armazenamento da informação espacial.

A documentação e os resultados gerados nesta pesquisa estão disponíveis no repositório denominado Base de Dados Científicos da Universidade Federal do Paraná (BDC-UFPR, 2019).

\section{MATERIAL E MÉTODO}

A metodologia da pesquisa foi realizada seguindo o processo de engenharia de requisitos (ER) aplicado a solução de geoinformação, conforme proposto por Sluter, Van Elzakker e Ivánová (2016). De forma geral, foram realizadas as atividades de elicitação, análise, especificação, validação e documentação de requisitos, para diagnosticar a situação encontrada em editais de licitação pública e criar um documento de requisitos de software padronizado capaz de apresentar uma proposta inicial de requisitos mínimos de um SIT, a fim de proporcionar o desenvolvimento de um sistema conforme a definição de SIT constante na Portaria 511/2009 do Ministério das Cidades (2009), que é a unificação, em um sistema informatizado, dos dados do cadastro territorial multifinalitário (CTM), correlacionados às informações constantes do registro de imóvel (RI) e dos dados de cadastros temáticos (MINISTÉRIO DAS CIDADES, 2009).

A Figura 1 ilustra esquematicamente o fluxo das etapas da metodologia aplicado na pesquisa.

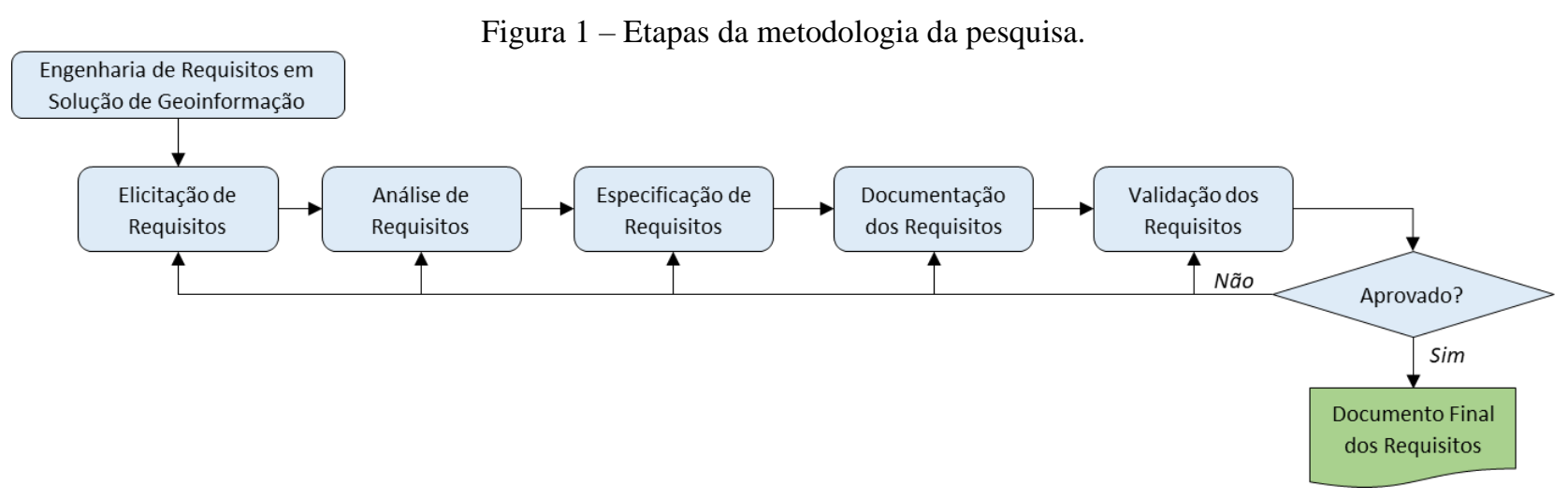

Fonte: Os autores (2021).

$\mathrm{Na}$ fase de elicitação e análise de requisitos foram determinadas as necessidades e as funcionalidades mínimas requeridas para um SIT, levando em consideração também as questões relacionadas à geoinformação, a partir da verificação de editais públicos, os quais tinham como objetivo a aquisição de produtos e serviços relacionados ao SIT. Como o estudo em questão tratou da definição dos requisitos de software mínimos de um SIT, considerou-se o contexto do sistema sendo a gestão territorial no âmbito da administração municipal. A 
especificação dos requisitos foi efetivada em um documento técnico, o qual apresenta os requisitos funcionais e não funcionais mínimos de um SIT como proposta inicial para uma padronização técnica. A validação dos requisitos é a última etapa do fluxo do processo de engenharia de requisitos e foi utilizada para verificar se o entendimento levantado e especificado está correto e, também, garantir que o documento de requisitos foi elaborado de modo consistente, completo, claro e objetivo (PRESSMAN, 2007).

Como principal material de pesquisa utilizou-se um conjunto de editais públicos de aquisição de soluções de geoinformação, SIG, software de geoprocessamento ou SIT disponível entre janeiro de 2016 a abril de 2019. Além da limitação temporal estabelecida, o escopo das funcionalidades modeladas foi restringido a um conjunto de módulos específicos e um número de requisitos limitado a fim de tornar a pesquisa exequível. Ao longo da execução da pesquisa foram catalogados e verificados 185 (cento e oitenta e cinco) editais públicos, os quais de alguma forma tinham como objetivo a aquisição de serviços e ou produtos relacionados a soluções de geoinformação. Este intervalo temporal foi estabelecido para que as especificações de sistemas fossem mais aderentes às tecnologias atuais, bem como houvesse maior praticidade em encontrar as publicações nos portais de transparências das instituições públicas.

\section{RESULTADOS E DISCUSSÕES}

O processo de catalogação e análise inicial dos editais de licitação, os quais, de alguma forma, traziam como seu objeto a aquisição de sistemas de informação geográfica com foco na gestão territorial urbana, permitiu quantificar e qualificar estes documentos, bem como registrar este catálogo em um documento no formato de planilha eletrônica ${ }^{1}$. A análise inicial mostrou que não há uma padronização na especificação dos produtos e ou serviços e há uma grande variação nas formas de apresentação dos requisitos técnicos. Mesmo assim, foi possível, através da aplicação das técnicas de elicitação e análise de requisitos, determinar as funcionalidades mais recorrentemente encontradas nos documentos analisados para propor um documento de requisitos padronizado. O conjunto total dos editais utilizados nesta pesquisa também foi estruturado em um repositório para permitir a comprovação dos dados levantados bem como dos resultados obtidos ${ }^{2}$.

Uma das análises realizadas sobre o conjunto de editais catalogados resultou na quantificação e qualificação destes documentos conforme a modalidade de licitação e o porte do município. Outra análise possível foi a verificação do volume de investimentos de recursos públicos, disponibilizados por administrações municipais, na aquisição de produtos e ou serviços relacionados à geoinformação no período analisado. Por meio da Tabela 1 e do Figura 2 constata-se que a modalidade de licitação mais recorrente entre os editais catalogados foi o pregão, a qual requer que o edital apresente uma especificação usual de mercado com padrões de desempenho e qualidade definidos objetivamente, de forma a qualificar o produto ou o serviço em um bem ou serviço comum (BRASIL, 2010). Além disso, os municípios de pequeno porte são os que mais optam pela modalidade de licitação pregão, a qual de forma geral requer o uso mais efetivo de especificações técnicas mais detalhadas, claras e objetivas.

Tabela 1 - Distribuição de editais segundo a modalidade de licitação e porte do município.

\begin{tabular}{|c|c|c|c|c|c|c|}
\hline \multirow{2}{*}{ Modalidade de licitação } & \multicolumn{4}{|c|}{ Porte do município } & \multirow{2}{*}{$\begin{array}{c}\text { Total de } \\
\text { editais }\end{array}$} & \multirow{2}{*}{$\begin{array}{l}\% \text { de } \\
\text { editais }\end{array}$} \\
\hline & Pequeno & Médio & Grande & Metrópole & & \\
\hline Concorrência pública & 12 & 9 & 29 & 4 & 54 & $29 \%$ \\
\hline Pregão & 52 & 12 & 16 & 2 & 82 & $44 \%$ \\
\hline Tomada de preço & 41 & 7 & 1 & 0 & 49 & $27 \%$ \\
\hline Total & 105 & 28 & 46 & 6 & 185 & $100 \%$ \\
\hline
\end{tabular}

Fonte: Os autores (2021).

\footnotetext{
${ }^{1}$ Documento disponível pelo DOI: <http://dx.doi.org/10.5380/bdc/37>.

${ }^{2}$ Repositório disponível para consulta por meio do DOI: 〈http://dx.doi.org/10.5380/bdc/36> .
} 
Figura 2 - Relação entre porte do município e modalidade de licitação.

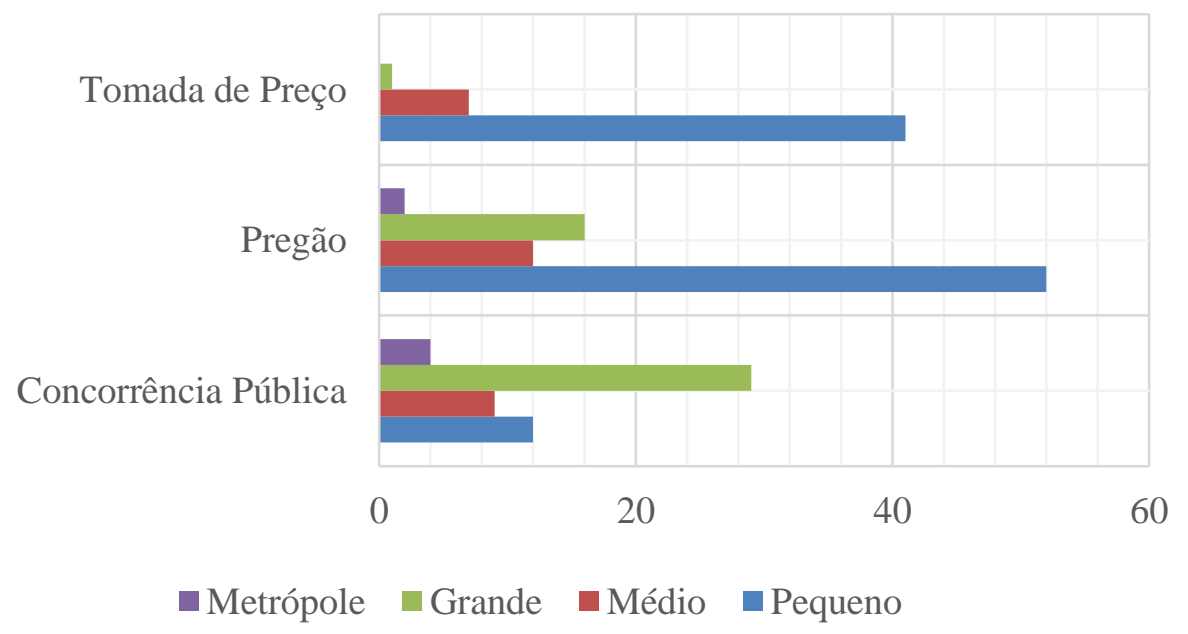

Fonte: Os autores (2021).

Em relação ao volume de investimentos de recursos públicos, conforme dados apresentados na Tabela 2, pôde-se determinar que a modalidade pregão não corresponde ao maior volume de investimentos, fato previsível uma vez que esta modalidade tem por objetivo celebrar contratações pelo menor custo. Contudo, representa uma fatia muito relevante do conjunto analisado e com expressivos valores previstos para investimento em produtos e ou serviços de geoinformação ao longo do período estudado.

Tabela 2 - Valores dos produtos e ou serviços dos editais segundo a modalidade de licitação e porte do município.

\begin{tabular}{l|r|r|r|r|r}
\hline \multirow{2}{*}{ Porte do município } & \multicolumn{2}{|c|}{ Valor total dos produtos e serviços por modalidade de licitação $(\mathbf{R} \$)$} & \multirow{2}{*}{ Totalização } & \multirow{2}{*}{$\begin{array}{l}\text { \% do } \\
\text { valor }\end{array}$} \\
\cline { 2 - 5 } & Concorrência pública & \multicolumn{1}{|c|}{ Pregão } & \multicolumn{1}{c}{ Tomada de preço } & \\
\hline Pequeno & $\mathrm{R} \$ 36.110 .372,48$ & $\mathrm{R} \$ 18.766 .352,41$ & $\mathrm{R} \$ 14.663 .784,92$ & $\mathrm{R} \$ 69.540 .509,81$ & $18,2 \%$ \\
Médio & $\mathrm{R} \$ 32.455 .481,89$ & $\mathrm{R} \$ 14.010 .696,26$ & $\mathrm{R} \$ 3.337 .483,29$ & $\mathrm{R} \$ 49.803 .661,44$ & $13,0 \%$ \\
Grande & $\mathrm{R} \$ 165.673 .542,77$ & $\mathrm{R} \$ 43.475 .155,22$ & $\mathrm{R} \$ 3.188 .792,91$ & $\mathrm{R} \$ 212.337 .490,90$ & $55,5 \%$ \\
Metróppole & $\mathrm{R} \$ 42.666 .209,01$ & $\mathrm{R} \$ 8.271 .298,50$ & $\mathrm{R} \$ 0,00$ & $\mathrm{R} \$ 50.937 .507,51$ & $13,3 \%$ \\
Totalização & $\mathrm{R} \$ 276.905 .606,15$ & $\mathrm{R} \$ 84.523 .502,39$ & $\mathrm{R} \$ 21.190 .061,12$ & $\mathrm{R} \$ 382.619 .169,66$ & $100 \%$ \\
\hline
\end{tabular}

Fonte: Os autores (2021).

A constatação de que a modalidade pregão vem sendo a mais utilizada pelas administrações públicas municipais, com investimentos de recursos relevantes para o setor de geoinformação, veio a confirmar a necessidade da existência de uma especificação técnica padronizada e usual de mercado, com critérios claros e objetivos, para a aquisição de serviços e produtos relacionados ao desenvolvimento e à implantação de um sistema de informação territorial.

Com a finalidade de verificar a distribuição geográfica dos editais de licitação catalogados, foi elaborado um mapa do número de editais por unidade da federação (UF) - ilustrado pela Figura 3 Distribuição de editais por unidade da federação. Figura 3 - no qual pode-se notar que as regiões Sudeste e Sul do Brasil são as que mais publicaram editais dentre os catalogados, com destaque para os estados de São Paulo e Paraná. Este fato pode estar relacionado com os seguintes fatores, que não foram objeto de pesquisa: a maior concentração de empresas, profissionais e instituições de ensino na área da geoinformação; e, por se tratar das regiões com maior produto interno bruto potencializando a concentração de renda e investimentos (IBGE, 2019). 
Figura 3 - Distribuição de editais por unidade da federação.

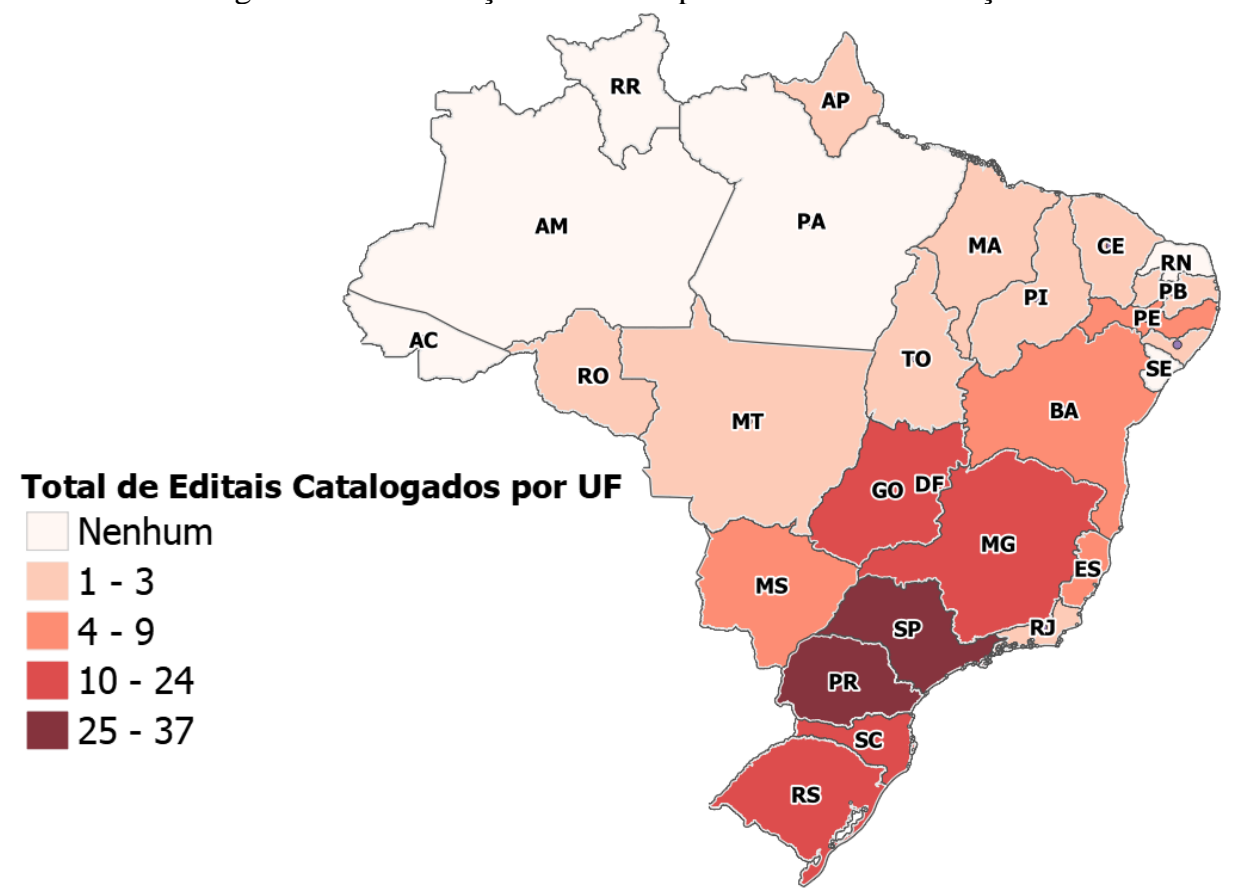

Fonte: Os autores (2021).

Sabendo que os valores monetários envolvidos na aquisição de produtos e ou serviços por administrações públicas requerem recursos públicos, optou-se por analisar a correlação do número de editais catalogados agrupados por unidade da federação com o poder econômico de cada unidade. Dentre os possíveis indicadores econômicos que medem a riqueza de uma região encontra-se o produto interno bruto (PIB), que é soma de todos os bens e serviços finais produzidos por um país, estado ou cidade, dentro de um período, geralmente um ano, o qual serve para medir o poder econômico de determinada região (IBGE, 2019; VICECONTI, NEVES, 2010). A partir dos dados oficiais publicados pelo IBGE em relação ao PIB de cada unidade da federação e os valores encontrados nos editais analisados, foi possível comprovar que o maior volume de recursos investidos está concentrado nas regiões com maior PIB, ou seja, onde há maior geração de riquezas há mais investimentos por parte das administrações públicas municipais em sistema de informações para gestão territorial urbana. A fonte de dados oficial mais recente disponível pelo IBGE, durante o estudo em questão, era do ano de 2015, por este motivo os dados foram analisados levando em consideração este ano. As cinco unidades federativas que mais apresentaram editais publicados no período entre janeiro de 2016 a abril de 2019, que foram objeto desta pesquisa, estão entre as dez maiores forças econômicas brasileiras. Entre as cinco maiores economias federativas brasileiras, apenas o estado do Rio de Janeiro não apresentou relevância na publicação de editais de interesse para esta pesquisa. A Figura 4 traz a ilustração de um mapa temático o qual correlaciona a quantidade de editais por modalidade de licitação agrupados por unidade da federação e o PIB de cada unidade federativa. 
Figura 4 - Modalidade de licitação e PIB da unidade da federação.

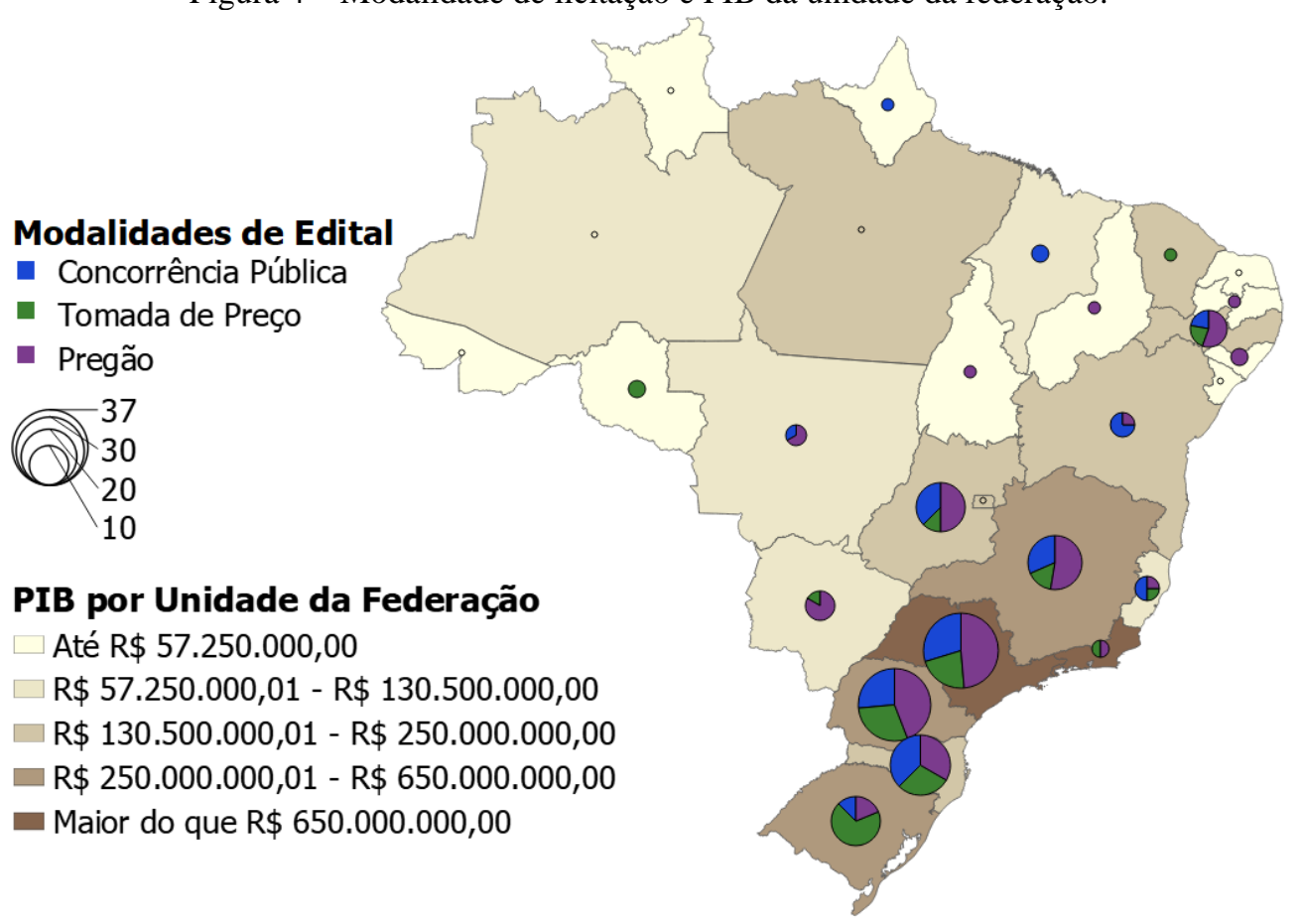

Fonte: Os autores (2021).

\subsection{Elicitação e Análise dos Requisitos}

A fim de identificar as atividades, dados e os processos que um SIT deve atender, foram aplicadas as técnicas de elicitação denominadas etnografia e documentação sobre o conjunto de editais catalogados entre janeiro de 2016 a abril de 2019. O uso das técnicas de etnografia e documentação foram empregadas neste estudo devido à limitação de utilização de outras técnicas, como a prototipagem, entrevistas com usuários e mapeamento de processos, uma vez que a etnografia é uma técnica de observação utilizada para compreender os processos operacionais e extrair os requisitos dos processos e a documentação é a técnica de compreensão dos requisitos a partir da leitura e análise de documentos disponíveis (SOMMERVILLE, 2011). Tais técnicas permitiram a concentração da pesquisa na análise documental disponível.

Para abranger um maior número de requisitos, processos e necessidades, bem como um conjunto maior de administrações públicas municipais, as técnicas de entrevistas com usuários e levantamentos de processos não foram viáveis para esta pesquisa, visto que o número de usuários possíveis e a quantidade de processos a serem mapeados em administrações públicas municipais seriam elevados dentro do tempo disponível para execução da pesquisa. Por isto, analisar documentos e identificar processos por meio de etnografia foram as técnicas mais adequadas para esta pesquisa. Tais técnicas permitiram levantar e listar as necessidades dos usuários do sistema e o contexto no qual o sistema está inserido sem a necessidade de um contato direto com as partes interessadas, permitindo que a pesquisa se concentre na análise documental disponível nos editais de licitação pública catalogados, fato que permitiu analisar um número de administrações públicas maior em um curto prazo de tempo. Dos 185 (cento e oitenta e cinco) editais de licitação catalogados apenas 135 (cento e trinta e cinco) foram empregados no processo de elicitação e análise, uma vez que foi necessário reservar um conjunto equivalente a 50 (cinquenta) editais, para serem utilizados na etapa de validação de requisitos, como editais de controle.

O fluxo de atividades para elicitação e análise de requisitos foi organizado e executado em quatro etapas, seguindo a proposta dos autores Sluter, Van Elzakker e Ivánová (2016): estabelecimento dos objetivos do sistema; entendimento do conhecimento técnico-científico; organização do conhecimento e coleta dos requisitos. Através da leitura e análise dos objetivos, justificativas e escopo dos trabalhos presentes nos editais, os objetivos do SIT puderam ser entendidos e definidos como sendo: organizar e disponibilizar bases de dados alfanuméricas e espaciais; implementar um cadastro territorial multifinalitário; associar dados cadastrais com registro de imóveis e cadastros temáticos; acompanhar o ordenamento e a ocupação do espaço territorial; e 
proporcionar ferramentas de gestão territorial. Por esta mesma análise, determinou-se o contexto do sistema como sendo a implementação de uma solução de tecnologia para administração pública municipal, que proporcione eficiência e eficácia na ordenação, no controle e na manutenção do espaço territorial e permita a conjugação de dados cadastrais, bases cartográficas e processos de gestão territorial. Baseado neste contexto e na análise documental, os usuários diretos identificados para utilização do sistema são gestores e técnicos municipais que buscam conhecimento da ocupação do território e do comportamento das alterações na ocupação territorial urbana para tomada de decisões, bem como requerem controlar, monitorar e manter os dados necessários para gestão territorial urbana.

Seguindo o fluxo de atividades do processo de elicitação, pôde-se definir que os principais conhecimentos técnicos envolvidos no desenvolvimento e na implantação de um sistema de informação territorial são: cadastro territorial multifinalitário, gestão territorial urbana e sistema de geoinformação. E para encerrar o fluxo, a organização do conhecimento e o levantamento dos requisitos requereu a verificação, análise e organização das informações descritivas constantes nos editais catalogados. Desta forma, para cada edital de licitação foram verificadas as descrições básicas de identificação do edital e toda a relação de itens de execução relacionados ao desenvolvimento e à implantação do sistema, relação esta que se tornou as funcionalidades levantadas como requisitos do sistema. $\mathrm{O}$ resultado das funcionalidades identificadas e organizadas, as quais foram desdobradas em requisitos do sistema, pode ser verificado no Quadro 1.

Quadro 1 - Lista de funcionalidades da etapa de elicitação de requisitos.

\begin{tabular}{|c|c|}
\hline Item & Lista de funcionalidades \\
\hline 1 & Apresentação da janela de mapa e da janela de dados para apresentação, consulta e manipulação dos dados. \\
\hline 2 & Disponibilização de ferramentas de manipulação e navegação da janela de mapa. \\
\hline 3 & $\begin{array}{l}\text { Apresentação dos dados de representação espacial que descrevam o espaço urbano. Os dados espaciais que serão ilustrados } \\
\text { pelo sistema deverão representar: limite do município, limites dos distritos, limites dos loteamentos, limites do zoneamento } \\
\text { urbano, limites dos bairros, limites dos setores fiscais, limites das quadras fiscais, limites dos imóveis, limites das } \\
\text { edificações, representação dos logradouros, representação das faces de quadras, representação da rede de abastecimento e } \\
\text { distribuição de água, representação da rede de energia, representação da rede de comunicação, representação da rede de } \\
\text { transporte público e representação da rede de iluminação pública. }\end{array}$ \\
\hline 4 & Apresentação de um mapa base de referência topográfica. \\
\hline 5 & Acesso aos atributos dos elementos de representação gráfica a partir da seleção do mesmo sobre a ja \\
\hline 6 & Associação dos elementos de representação gráfica dos imóveis com os dados cadastrais. \\
\hline 7 & $\begin{array}{l}\text { Associação os elementos de representação gráfica dos imóveis com os dados do registro de imóveis, por meio de } \\
\text { integração e interoperabilidade de dados; }\end{array}$ \\
\hline 8 & $\begin{array}{l}\text { Associação de documentos aos elementos de representação gráfica do imóvel, do logradouro, do loteamento, do } \\
\text { zoneamento urbano e os da infraestrutura urbana. }\end{array}$ \\
\hline 9 & Integração com o sistema de gestão tributária da administração pública municipal. \\
\hline 10 & $\begin{array}{l}\text { Integração com os sistemas internos e das concessionárias responsáveis pela rede de água, rede de energia, rede de } \\
\text { comunicação, rede de transporte público e iluminação pública. }\end{array}$ \\
\hline 11 & Apresentação dos atributos dos elementos de representação gráfica em uma janela de dados. \\
\hline 12 & Realização de consulta por atributos vinculados aos elementos gráficos de uma classe de feição. \\
\hline 13 & Realização de consultas e operações espaciais entre elementos gráficos das classes de feição. \\
\hline 14 & Disponibilização de ferramentas para medir distâncias, áreas e coordenadas. \\
\hline 15 & $\begin{array}{l}\text { Realização do controle das classes que serão apresentadas, bem como do nível de transparência das mesmas, na janela de } \\
\text { mapa através de interações com a legenda do mapa. }\end{array}$ \\
\hline 16 & $\begin{array}{l}\text { Disponibilização das funcionalidades de gestão do cadastro de distritos, bairros, loteamentos, zoneamento urbano, } \\
\text { infraestrutura urbana, setores fiscais, quadras fiscais, imóveis ou parcelas, edificações, logradouros e trechos de } \\
\text { logradouros. }\end{array}$ \\
\hline 17 & Disponibilização das funcionalidades de gestão do cadastro de pessoas e ou contribuintes. \\
\hline 18 & $\begin{array}{l}\text { Disponibilização de funcionalidades para associação de responsáveis, documentos e logradouros ao imóvel como forma } \\
\text { de complementação das funcionalidades de gestão cadastral. }\end{array}$ \\
\hline 19 & Controle de acesso aos dados por grupos, perfis e usuários. \\
\hline 20 & Controle das operações realizadas no sistema para auditoria. \\
\hline 21 & Criação e impressão da ficha cadastral do imóvel com apresentação de dados alfanuméricos e espaciais. \\
\hline 22 & o e impressão da certidão de confrontantes do imóvel com apresentação de dados alfanuméricos e espaciais. \\
\hline 23 & Criação e impressão do memorial descritivo do imóvel com apresentação de dados alfanuméricos e espaciais. \\
\hline 24 & Criação e impressão do relatório dos imóveis vinculados a um logradouro. \\
\hline 25 & Criação e impressão do relatório de viabilidade de parcelamento do solo. \\
\hline 26 & Criação e impressão do relatório de viabilidade de funcionamento de atividades. \\
\hline 27 & Criação e impressão dos imóveis e condomínios associados a uma pessoa. \\
\hline 28 & Exportação de dados gráficas e alfanuméricos. \\
\hline 29 & ção de dados dos imóveis, dos logradou \\
\hline 30 & \\
\hline
\end{tabular}


Fonte: Os autores (2021).

A etapa de análise dos requisitos objetivou compreender as funcionalidades e as necessidades dos usuários e definir os requisitos mínimos necessários para uma proposta técnica preliminar do sistema. Para se definir a real necessidade de uma funcionalidade ou restrição do sistema, foram definidos questionamentos sobre os quais identificou-se a sua real relevância dentro do contexto do sistema. Os questionamentos realizados para determinar a relevância de um requisito foram os seguintes: $\mathrm{O}$ requisito está claro e bem definido no edital? O requisito é real e factível de ser implementado? Cada requisito descreve algo essencial para o SIT? O requisito foi encontrado em um número significativo de editais? Com base nas respostas encontradas, para cada funcionalidade identificada como um requisito, e utilizando-se da prática de checklist e resolução de conflitos, foi possível determinar o conjunto mínimo de requisitos mais relevantes e recorrentes constantes nos documentos analisados. A lista de requisitos funcionais e não funcionais definidos como solução mínima para aquisição e implantação de um SIT, gerada com a conclusão da etapa de análise de requisito, foi estruturada em um documento para utilização na etapa de especificação e documentação ${ }^{3}$. A Tabela 3 apresenta um resumo geral quantitativo do conjunto de requisitos analisados agrupados por módulos, no qual observa-se que foram identificados 38 requisitos não funcionais e 205 funcionais, sendo que houve a necessidade de agrupar os requisitos funcionais em seis módulos específicos e um módulo central.

Tabela 3 - Resumo quantitativo da etapa de elicitação de requisitos.

\begin{tabular}{|c|c|}
\hline Requisitos & Total de requisitos \\
\hline Não funcional & 38 \\
\hline Funcional & 205 \\
\hline Módulo & Total de requisitos funcionais \\
\hline Central & 45 \\
\hline Cadastro imobiliário & 57 \\
\hline Cadastro de logradouro & 22 \\
\hline Cadastro de loteamento & 18 \\
\hline Cadastro de infraestrutura urbana & 24 \\
\hline Cadastro de parcelamento do solo & 21 \\
\hline Cadastro de pessoa & 18 \\
\hline
\end{tabular}

Fonte: Os autores (2021).

O Módulo Central é dedicado a expor as funcionalidades básicas para a implantação do SIT, que são requeridas em qualquer outro módulo específico. O Módulo Cadastro Imobiliário expõe funcionalidades específicas para gestão do cadastro imobiliário. As funcionalidades específicas para gestão do cadastro de logradouro estão contidas no Módulo Cadastro de Logradouro. O Módulo Loteamento concentra funcionalidades específicas para gestão do cadastro de loteamento. Funcionalidades para gestão da infraestrutura urbana concentram-se no Módulo de Infraestrutura Urbana. O Módulo de Parcelamento do Solo expõe funcionalidades específicas para gestão do cadastro de parcelamento do solo e zoneamento urbano, conciliando as diretrizes do plano diretor municipal com cadastro imobiliário e de loteamento. E, o Módulo Cadastro de Pessoa contém funcionalidades específicas para gestão de pessoa.

\subsection{Especificação e Documentação dos Requisitos}

A especificação e documentação de requisitos é a etapa da engenharia de requisitos que consolida e documenta tecnicamente o processo de elicitação e análise dos requisitos (SOMMERVILLE, 2011; PRESSMAN, 2007). A descrição formal de um requisito, que corresponde à tarefa principal da especificação, deve permitir o entendimento claro e objetivo do mesmo, bem como apresentar as possíveis ligações entre os requisitos (RAMOS, 2016). O uso de padrões de especificação de requisitos é comum para alcançar a clareza e a objetividade necessárias na especificação de um requisito. Dentre os padrões disponíveis há o ISO/IEC/IEEE que é exposto pela norma ISO 29.148:2011, o qual foi utilizado e possibilitou estruturar os requisitos deste estudo. A norma ISO 29.148:2011 especifica os processos necessários implementados nas atividades de engenharia de software, que resultam em requisitos para sistemas e produtos de software,

\footnotetext{
${ }^{3}$ Documento disponível pelo DOI: 〈http://dx.doi.org/10.5380/bdc/38 >.
} 
incluindo serviços, ao longo do ciclo de vida, fornece diretrizes para a aplicação dos requisitos e processos relacionados aos requisitos necessários para descrição de sistemas e produtos de software, especifica os itens de informação necessários produzidos através da implementação dos processos de requisitos; define o conteúdo necessário dos itens de informação requeridos por sistemas e produtos de software e fornece diretrizes para o formato do documento de apresentação de requisitos e especificação técnica de softwares (ISO, 2011).

O desenvolvimento, a aquisição e a implantação de um SIT requerem um conjunto mínimo de funcionalidades, as quais foram especificadas de forma modular e por questões de limitações de abrangência do escopo da pesquisa, optou-se por especificar, descrever e documentar apenas três módulos para o SIT: Central, Cadastro Imobiliário e Cadastro de Logradouro. Estes três módulos concentram as funcionalidades mais recorrentes verificadas no processo de elicitação e análise de requisitos, bem como são os módulos que contêm as funcionalidades básicas para auxiliar na implantação do Cadastro Territorial Multifinalitário (CTM), na integração com o registro de imóveis e na gestão do cadastro imobiliário e de logradouro, indo ao encontro da definição de SIT constante na Portaria 511/2009 do Ministério das Cidades. Para tornar a especificação dos requisitos mais clara e objetiva também foram projetados casos de uso. Para Larman (2000), caso de uso é uma técnica para melhorar a compreensão dos requisitos do sistema a partir de narrativas de processos. Por esse motivo, optou-se pela criação e descrição dos casos de uso inerentes às funcionalidades mínimas levantadas para a aquisição e implantação do SIT. Todos os casos de uso projetados como solução do processo de especificação foram sistematizados e documentados a fim de formalizar o resultado do processo de especificação dos requisitos ${ }^{4}$.

A documentação dos requisitos correspondeu à atividade de compilação das especificações elaboradas em um único documento. O documento de requisitos é a declaração oficial do que é exigido do sistema e correspondeu ao produto final do processo de ER aplicado nesta pesquisa. A Figura 5 esboça a estrutura geral do documento de requisito criado, a fim de apresentar os requisitos mínimos de um SIT para administrações públicas municipais como uma proposta básica e inicial. Como a descrição dos requisitos e os detalhes técnicos propostos são extensos, optou-se por não os apresentar neste artigo, e apenas demonstrar a estrutura sugerida como uma proposta de documentação inicial ${ }^{4}$.

Figura 5 - Estrutura do documento de requisitos.

\begin{tabular}{|l|}
\hline 1. Introdução \\
1.1 Propósito do Sistema \\
1.2 Escopo do Sistema \\
1.3 Visão Geral do Sistema \\
1.3.1 Contexto do Sistema \\
1.3.2 Funções do Sistema \\
1.3.3 Características do Usuário \\
2. Requisitos do Sistema \\
2.1 Requisitos Funcionais \\
2.2 Requisitos Não Funcionais \\
\hline
\end{tabular}

Fonte: Adaptada de ISO (2011).

\subsection{Validação dos Requisitos}

$\mathrm{Na}$ etapa de validação de requisitos foram empregadas as técnicas manuais de leitura, referência cruzada e lista de verificação e a técnica automatizada de referência cruzada, dentre as propostas por Pfleeger (2004). O modo de validação dos requisitos executado baseou-se na confrontação dos itens especificados e documentados com os requisitos presentes no conjunto de editais catalogados para controle, os quais não fizeram parte das atividades de elicitação e análise para a elaboração da proposta inicial mínima de requisitos, a fim de verificar se os mesmos atendem aos objetivos e ao contexto estabelecidos para um SIT. Deste modo,

\footnotetext{
${ }^{4}$ Documento disponível pelo DOI: 〈http://dx.doi.org/10.5380/bdc/44>.
} 
uma lista de verificação ${ }^{5}$, contendo todos os requisitos especificados foi elaborada para que através de leitura, verificação e cruzamento de dados fosse constatada a presença do requisito nos editais selecionados para sua validação. Cabe ressaltar, que no processo de validação ao todo foram considerados 124 (cento e vinte e quatro) requisitos funcionais, os quais correspondem aos requisitos mínimos propostos e especificados para aquisição, desenvolvimento e implantação dos Módulos Central, Cadastro Imobiliário e Cadastro de Logradouro, e 38 (trinta e oito) requisitos não funcionais.

Os editais que serviram de fonte de dados para validação dos requisitos foram selecionados dentre os 185 (cento e oitenta e cinco) catalogados. Como os editais na modalidade pregão corresponderam a $44 \%$ (quarenta e quatro por cento), com um total de 82 (oitenta e dois) editais dentre os catalogados, tomou-se a decisão de validar os requisitos projetados como mínimos para um SIT sobre um conjunto equivalente a $60 \%$ (sessenta por cento) dos editais na modalidade pregão, o que correspondeu a 50 (cinquenta) editais.

A Tabela 4 apresenta o conjunto de editais na modalidade pregão, de acordo com o porte do município e o ano da publicação, catalogados na pesquisa, por meio da Tabela 4 percebe-se a maior concentração de editais na modalidade pregão publicados por municípios de pequeno porte e consequentemente no processo de validação, cuja seleção foi realizada de forma proporcional e aleatória. A distribuição geográfica dos editais na modalidade pregão por unidade da federação (UF), selecionados no processo de validação apresentou o mesmo comportamento identificado no conjunto total de editais catalogados, conforme apresentado na Figura 3, provavelmente pelos mesmos motivos descritos anteriormente.

Tabela 4 - Distribuição dos editais na modalidade pregão do processo de validação ${ }^{6}$.

\begin{tabular}{|c|c|c|c|c|c|c|c|}
\hline \multirow{3}{*}{ Porte do município } & \multicolumn{7}{|c|}{ Edital na modalidade pregão } \\
\hline & \multicolumn{4}{|c|}{ Ano de publicação } & \multirow{2}{*}{ Total } & \multirow{2}{*}{$\%$} & \multirow{2}{*}{$\begin{array}{c}\text { Quantidade para } \\
\text { validação }\end{array}$} \\
\hline & 2016 & 2017 & 2018 & 2019 & & & \\
\hline Pequeno & 5 & 36 & 6 & 5 & 52 & $63,4 \%$ & 32 \\
\hline Médio & 3 & 5 & 3 & 1 & 12 & $14,6 \%$ & 7 \\
\hline Grande & 3 & 8 & 4 & 1 & 16 & $19,5 \%$ & 10 \\
\hline Metrópole & 0 & 0 & 2 & 0 & 2 & $2,4 \%$ & 1 \\
\hline Total & 11 & 49 & 15 & 7 & 82 & $100 \%$ & 50 \\
\hline
\end{tabular}

Fonte: Os autores (2021).

Para validar os requisitos especificados, primeiramente foi realizada uma análise mais detalhada, sobre os editais selecionados para validação, aplicando os seguintes questionamentos: Há uma lista de requisitos no edital? Há uma classificação para identificação de um requisito funcional no edital? Há uma classificação para identificação de um requisito não funcional no edital? Há divisão em módulos para os requisitos no edital? Há um documento de requisitos formal no edital? O requisito possui título claro e resumido? O requisito possui descrição? Há justificativa de se adotar tal requisito? Descreve-se ligação e dependência com outros requisitos?

O resultado da aplicação dos questionamentos pode ser visto na Tabela 5. Nota-se que foi possível identificar requisitos funcionais e não funcionais em uma proporção relativamente alta, contudo os itens que permitem tornar os requisitos mais bem definidos e claros (linhas H e I na Tabela 5), de modo geral, não foram apresentados nos editais e em nenhum edital analisado pôde-se constatar a presença de um documento de requisitos padronizado e formalizado, como é visto na linha $\mathrm{E}$ da Tabela 5. Também foi possível verificar o grau de similaridade dos requisitos contidos nos documentos analisados, tal similaridade foi definida pela quantidade de requisitos cuja descrição ou titulação são idênticos ou semelhantes. Dos 50 (cinquenta) editais selecionados apenas 18 (dezoito) podem ser considerados sem similaridade e os demais 32 (trinta e dois), ou seja $64 \%$, possuem algum grau de similaridade com pelo menos um outro documento, este fato mostra que os documentos analisados possuem uma tendência de ser semelhantes, descrevendo propósitos e contextos muito parecidos, mesmo sabendo que cada administração pública municipal tem particularidades e especificidades relacionadas a seu grau de desenvolvimento, sua capacidade técnica e de infraestrutura, bem como, seu conhecimento e maturidade no uso de geotecnologias e geoinformação, contudo esta pesquisa não pôde levantar as possíveis condições que possam confirmar e validar esta tendência.

\footnotetext{
${ }^{5}$ Documento disponível pelo DOI: < http://dx.doi.org/10.5380/bdc/40>.

${ }^{6}$ Dados compilados a partir do documento disponível pelo DOI: <http://dx.doi.org/10.5380/bdc/39>.
} 
Tabela 5 - Resumo da análise dos editais selecionados para validação dos requisitos.

\begin{tabular}{|c|c|c|c|}
\hline Item & Descrição & Total & $\%$ \\
\hline A & Número de Editais com Requisitos & 50 & $100 \%$ \\
\hline B & Número de Editais com Requisitos Funcionais & 47 & $94 \%$ \\
\hline $\mathrm{C}$ & Número de Editais com Requisitos Não Funcionais & 48 & $96 \%$ \\
\hline $\mathrm{D}$ & Número de Editais com Requisitos Modularizados & 14 & $28 \%$ \\
\hline $\mathrm{E}$ & Número de Editais com Documentação de Requisitos & 0 & $0 \%$ \\
\hline $\mathrm{F}$ & Número de Editais com Título de Requisitos & 23 & $46 \%$ \\
\hline G & Número de Editais com Descrição de Requisitos & 36 & $72 \%$ \\
\hline $\mathrm{H}$ & Número de Editais com Justificativa dos Requisitos & 0 & $0 \%$ \\
\hline I & Número de Editais com Dependência dos Requisitos & 0 & $0 \%$ \\
\hline
\end{tabular}

Fonte: Os autores (2021).

Após a análise anterior, o próximo passo executado foi a comparação de cada edital de modo a constatar a presença ou não dos requisitos especificados. Cada edital selecionado para fazer parte das atividades de validação dos requisitos teve seus requisitos identificados, catalogados e classificados para permitir a confrontação destes com os propostos nesta pesquisa. Os resumos dos resultados do processo de validação dos requisitos podem ser vistos a partir da Tabela 6 . Conforme a Tabela 6 , o resultado da validação dos requisitos funcionais propostos, como uma solução de engenharia de requisitos para especificação de módulos específicos de um SIT, mostrou que $91 \%$ (noventa e um por cento) destes foram correlacionados com algum dos editais selecionados para validação dos requisitos. Constata-se também que aproximadamente 58\% (cinquenta e oito por cento) dos requisitos não funcionais foram correlacionados com algum dos editais selecionados para validação dos requisitos. Este fato comprova a percepção encontrada na fase de elicitação e análise de requisitos de que não há maiores preocupações na determinação das restrições do sistema ou do domínio, as quais possam se tornar requisitos não funcionais relevantes.

Tabela 6 - Resumo da validação dos requisitos funcionais e não funcionais propostos.

\begin{tabular}{c|c|c|c|c}
\hline $\begin{array}{c}\text { Total de requisitos } \\
\text { propostos }\end{array}$ & $\begin{array}{c}\text { Total de requisitos propostos } \\
\text { associados aos editais }\end{array}$ & $\begin{array}{c}\text { Total de requisitos propostos não } \\
\text { associados aos editais }\end{array}$ & $\begin{array}{c}\text { Índice de } \\
\text { validação }\end{array}$ \\
\hline \multicolumn{7}{|c|}{ Funcionais } & 11 & $91 \%$ \\
\hline 124 & $113 \quad$ Não funcionais & 16 & $58 \%$ \\
\hline 38 & 22 & & 16 & \\
\hline
\end{tabular}

Fonte: Os autores (2021).

De posse do número total de requisitos identificados no edital e do número de requisitos que corresponderam a um requisito proposto foi possível determinar a taxa de ocorrência de requisitos propostos sobre o material de validação, que foi denominado de índice de requisitos previstos no modelo. Este índice variou de 0,13 a 1,00, indicado que houve editais com baixa correspondência aos requisitos propostos e editais com total correspondência. A Tabela 7 e o Figura 6 apresentam o agrupamento dos valores dos índices obtidos nesta análise e é possível verificar que a maioria dos editais analisados possuem índice entre 0,25 a 0,50 , sendo que o índice médio encontrado foi de 0,44 e a média dos índices determinada foi de 0,52.

Tabela 7 - Taxa de associação dos requisitos propostos.

\begin{tabular}{c|c|c}
\hline Faixa do índice de requisitos previstos no modelo & Frequência de editais & Frequência relativa de editais \\
\hline 0,00 a 0,25 & 06 & $12 \%$ \\
0,25 a 0,50 & 20 & $40 \%$ \\
0,50 a 0,75 & 14 & $28 \%$ \\
0,75 a 1,00 & 10 & $20 \%$ \\
\hline
\end{tabular}

Fonte: Os autores (2021). 
Figura 6 - Taxa de associação dos requisitos propostos.

\section{Índice de Requisitos Previstos no Modelo}

25

20

15

10

5

0

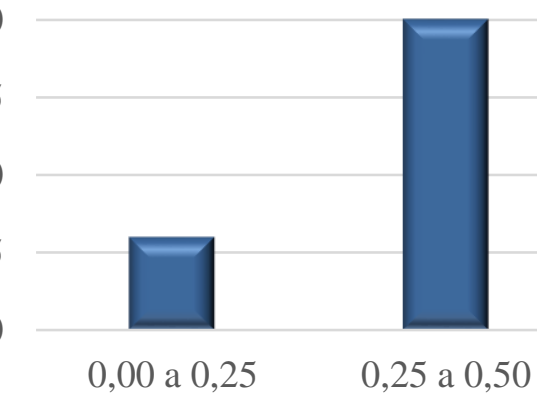

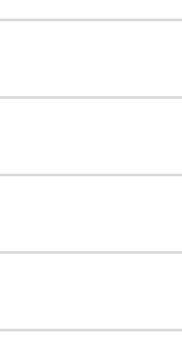

0,50 a 0,75

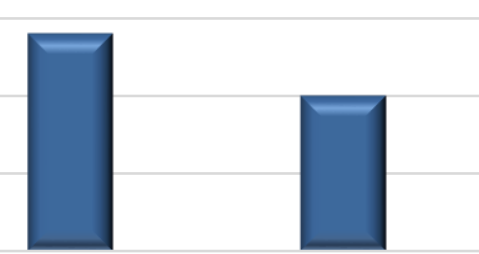

0,75 a 1,00

Fonte: Os autores (2021).

$50 \%$

$40 \%$

$30 \%$

$20 \%$

$10 \%$

$0 \%$
Frequência de Editais

Frequência

Relativa de

Editais

Considerando que os requisitos propostos perfizeram um total de 162 (cento e sessenta e dois) - entre funcionais e não funcionais - mas que corresponderam apenas àqueles projetados para os Módulos Central, Cadastro Imobiliário e Cadastro de Logradouro, e que pela elicitação e análise de requisitos determinou-se um conjunto total de requisitos de 243 (duzentos e quarenta e três) para todos os módulos, os valores encontrados para a taxa de associação dos requisitos propostos ficaram dentro de proporções aceitáveis. Os resultados obtidos com as atividades de validação dos requisitos mostraram que há uma aderência na proposta apresentada em relação à amostra dos editais selecionados para verificação, já que 48\% dos editais apresentaram índice de requisitos igual ou superior a 0,50 .

\section{CONCLUSÕES E RECOMENDAÇÕES}

Com esta pesquisa buscou-se evidenciar o crescente uso da modalidade pregão também nos processos licitatórios de aquisição e implantação de soluções de geoinformação para gestão territorial urbana, bem como determinar a ausência de especificações usuais de mercado, com definição clara e objetiva dos requisitos para tais soluções, fator essencial para uso desta modalidade de licitação. Tais especificações, as quais permitam classificar um produto ou um serviço como um bem ou serviço comum, constituem um requisito essencial para que qualquer administração pública possa fazer uso da modalidade pregão em um processo licitatório.

A partir da aplicação da metodologia proposta, fazendo utilização do fluxo de engenharia de requisitos (ER) aplicado a soluções de geoinformação, foi possível evidenciar os seguintes aspectos: há efetivamente maior uso da modalidade pregão nos processos licitatórios; os editais na modalidade pregão analisados não apresentam de forma clara e objetiva os requisitos de sistema com especificações usuais de mercado; não há uma documentação de requisitos de sistema formal e usual de mercado nos editais analisados; foi possível determinar uma solução de ER compatível com as necessidades identificadas no material analisado para um conjunto específico de módulos de sistema; a solução proposta pôde ser validada e constatou-se a sua aderência às necessidades encontradas; e, um documento de requisitos pôde ser criado como uma solução padronizada e usual de mercado para especificação de uma proposta inicial de módulos específicos de um SIT.

Considerando os resultados alcançados, pôde-se concluir que o cenário brasileiro para os editais de licitação pública de sistema de informação territorial para administrações municipais não apresenta especificações técnicas adequadas à modalidade de licitação. Além disso, o uso de ER na criação de documentação e especificação técnica para soluções de geoinformação aplicadas à gestão territorial, como o sistema de informação territorial em estudo, permitiu alcançar o objetivo geral da pesquisa e forneceu um conjunto de requisitos de sistema como proposta inicial para aquisição de módulos específicos de um SIT por administração pública municipal.

Como recomendações para estudos futuros destacam-se os seguintes pontos: determinar os fatores que venham a confirmar ou não a tendência de similaridade nas especificações técnicas publicadas por administrações públicas municipais; estender a descrição e a documentação dos requisitos abrangendo os 
demais módulos; projetar e validar um diagrama de classes a partir do documento de requisitos; projetar e validar um modelo de dados geográfico; projetar e especificar requisitos funcionais e não funcionais relacionados aos aspectos da geovisualização; e, implementar, implantar e validar um SIT a partir do documento de requisitos apresentado nesta pesquisa como proposta inicial.

\section{Agradecimentos}

A autora Luciene Stamato Delazari agradece ao Conselho Nacional de Desenvolvimento Científico e Tecnológico pela concessão da Bolsa Produtividade em Pesquisa (CNPq -Processo no 310312 / 2017-5).

\section{Contribuição dos Autores}

O autor Everton Leandro Nubiato contribuiu na conceptualização, análise formal, investigação metodologia, recursos, validação e redação. A autora Luciene Stamato Delazari contribuiu na supervisão, metodologia, validação e redação.

\section{Conflitos de Interesse}

Os autores declaram que não há conflito de interesse.

\section{Referências}

AMORIM, J. J.; SILVA, M. A.; RESENDE, P. O.; SOUZA, P. H. Cadastro Técnico: Uma Ferramenta de Gestão Territorial para Municípios de Pequeno Porte. Revista MundoGeo, Curitiba, 2015. Disponível em: <http://mundogeo.com/blog/2015/ 07/20/cadastro-tecnico-uma-ferramenta-de-gestao-territorial-paramunicipios-de-pequeno-porte/>. Acessado em: 10 ago. 2018.

BASE DE DADOS CIENTÍFICOS DA UNIVERSIDADE FEDERAL DO PARANÁ (BDC-UFPR). Repositório Institucional Digital da Universidade Federal do Paraná. Disponível em: <https://bdc.c3sl.ufpr.br/ >. Acessado em: 10 jun. de 2019.

BRASIL. Constituição (1988). Constituição: República Federativa do Brasil. Brasília, DF: Senado Federal, 1988.

BRASIL. Lei Federal no 8.666 de 21 de junho de 1993. Regulamenta o art. 37, inciso XXI, da Constituição Federal, institui normas para licitações e contratos da Administração Pública e dá outras providências. Diário Oficial da União, Brasília, DF, 22 jun. 1993. Disponível em: <http://www.planalto.gov.br/ccivil_03/Leis/L8666cons.htm >. Acessado em: 11 ago. de 2018.

BRASIL. Lei Complementar Federal no 101 de 04 de maio de 2000. Estabelece normas de finanças públicas voltadas para a responsabilidade na gestão fiscal e dá outras providências. Diário Oficial da União, Brasília, DF, 05 mai. 2000.2 Disponível <http://www.planalto.gov.br/ccivil_03/Leis/LCP/Lcp101.htm>. Acessado em: 11 ago. de 2018.

BRASIL. Lei Federal no 10.257 de 10 de julho de 2001. Regulamenta os artigos 182 e 183 da Constituição Federal; estabelece diretrizes gerais da política urbana e dá outras providências. Denominada de Estatuto da Cidade. Diário Oficial da União, Brasília, DF, 11 jul. 2001. Disponível em: <http://www.planalto.gov.br/ccivil_03/leis/LEIS_2001/L10257.htm>. Acessado em: 11 ago. de 2018.

BRASIL. Lei Federal n ${ }^{\circ} 10.520,17$ de junho de 2002. Institui, no âmbito da União, Estados, Distrito Federal e Municípios, nos termos do art. 37, inciso XXI, da Constituição Federal, modalidade de licitação denominada pregão, para aquisição de bens e serviços comuns, e dá outras providências. Diário Oficial da União, Brasília, DF, 18 jul. 2002. Disponível em: <http://www.planalto.gov.br/ccivil_03/LEIS/2002/L10520.htm. Acessado em: 11 ago. de 2018.

BRASIL. Nota Técnica No 02/2008 - SEFTI/TCU. Tribunal de Contas da União. Brasília, DF, 11 set. 2008. 
Disponível em: <https://revista.tcu.gov.br/ojs/index.php/RTCU/article/view/284/297>. Acessado em: 11 ago. de 2018.

ERBA, D. A.; LIMA JUNIOR, P. N.; OLIVEIRA, F. L. Cadastro Multifinalitário como Instrumento de Política Fiscal e Urbana. Rio de Janeiro: 2005. p. 15-38. Disponível em: <http://www.capacidades.gov.br/biblioteca/detalhar/id/78/titulo/cadastro-multifinalitario-comoinstrumento-de-politica-fiscal-e-urbana>. Acessado em: 12 ago. 2018.

INSTITUTO BRASILEIRO DE GEOGRAFIA E ESTATÍSTICA (IBGE). Produto Interno Bruto - PIB. Disponível em: 〈https://www.ibge.gov.br/explica/pib.php〉. Acessado em: 10 fev. 2019.

INTERNATIONAL ORGANIZATION FOR STANDARDIZATION (ISO). ISO 29.148: System and Software Engineering - Life Cycle Processes - Requirements Engineering. Geneva, 2011.

LARMAN, G. Utilizando UML e Padrões. 1 ${ }^{a}$ Edição. Porto Alegre: Bookman, 2000.

MINISTÉRIO DAS CIDADES. Portaria 511, de 07 de dezembro de 2009. Diretrizes para a criação, instituição e atualização do Cadastro Territorial Multifinalitário (CTM) nos municípios brasileiros. Diário Oficial da União, Brasília, DF, 08 dez. 2009. Disponível em: <https://www.normasbrasil.com.br/norma/portaria511-2009_217279.html>. Acessado em: 12 ago. 2018.

PFLEEGER, S. L. Engenharia de Software: Teoria e Prática. $2^{\text {a }}$ edição. São Paulo: Pearson, 2004.

PRESSMAN, R. S. Engenharia de Software. $6^{\text {a }}$ edição. São Paulo: McGraw-Hill, 2007.

RAMOS, G. D. Determinação das Características da Geoinformação na Interação do Usuário em um Sistema para o Cálculo da Contribuição de Melhoria. 133 f. Dissertação (Mestrado em Ciências Geodésicas). Universidade Federal do Paraná, Curitiba, 2016.

SCARASSATTI, D. F., RAMÍREZ, E. J., COSTA, D. C., TRABANCO, J. L. A. Cadastro Multifinalitário e a Estruturação de Sistemas de Informações Territoriais. Congresso Brasileiro de Cadastro Técnico Multifinalitário, 2014, Florianópolis. Anais. Disponível em: <http://www.catastrolatino.org/documentos/Scarassatti_Ramirez_Costa_Trabanco.pdf> ou <https://repositorio.ufsc.br/xmlui/handle/123456789/132337>. Acessado em: 12 ago. 2018.

SLUTER, C. R., VAN ELZAKKER, C. P. J. M., IVÁNOVÁ, I. Requirements Elicitation for Geo-Information Solutions. The Cartographic Journal. London, v. 54, n. 1, p. 77-90, June 2016. DOI 10.1179/1743277414Y.0000000092. Acessado em: 15 set. 2018.

SOMMERVILLE, I. Engenharia de Software. 9a edição. São Paulo: Person, 2011.

VICECONTI, P. E. V., NEVES, S. Introdução à Economia. 10ª edição, São Paulo, 2010.

\section{Biografia do autor principal}

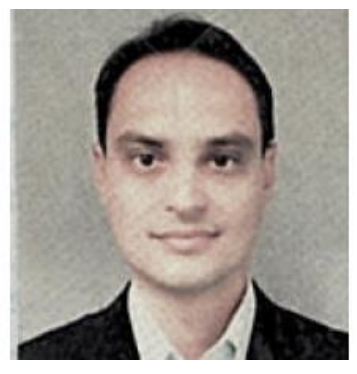

Everton Leandro Nubiato, brasileiro, nascido na cidade de Fernandópolis, São Paulo. É graduado em Engenharia Cartográfica pela Universidade Estadual Paulista (UNESP), Especialista em Geotecnologias pela Universidade Federal do Paraná (UFPR), Especialista em Governança de Tecnologia da Informação pelo Serviço Nacional de Aprendizagem Comercial do Paraná (Senac/PR) e Mestre em Ciências Geodésicas pela Universidade Federal do Paraná (UFPR). É gerente de projetos certificado pelo Project Management Institute (PMI) e coordenador de desenvolvimento de sistemas na empresa Engefoto Engenharia e Aerolevantamentos S.A. Possui experiência em prospecção, concepção, modelagem, desenvolvimento e implantação de soluções de geoinformação e gestão territorial. 